\title{
A Maçonaria no espaço insular atlântico português: As origens católicas da maçonaria madeirense
}

\section{The Freemasonry in the Island Space of Portuguese Atlantic: The Catholic origins of Madeiran Freemasonry}

\author{
José Eduardo Franco \\ Universidad Abierta, Portugal \\ eduardofranco.cidh@gmail.com \\ Fernanda Santos \\ Universidad Federal de Amapá, Brasil \\ fercris77@gmail.com
}

Recepción: 19 de marzo de 2018/Aceptación: 30 de abril de 2018.

doi: https://doi.org/10.15517/rehmlac.v10i1.32771

Palavras chave

Maçonaria; clero; igreja; madeira; elites.

Keywords

Freemasonry; Clergy; Church; Madeira Island; Elites.

Resumo

Séculos de polémicas, proibições e ataques mútuos tornaram a Maçonaria e a Igreja Católica uma espécie de adversários irreconciliáveis. Não obstante, não deixa de ser paradoxal a atração que a Maçonaria exerceu sobre membros da Igreja. Nas fileiras da maçonaria e, em particular, nos quadros das lideranças maçónicas, contaram-se membros provindos da Igreja Católica, nomeadamente do seu clero secular e regular. Se isto foi verdade a nível internacional, foi, mais ainda, de modo especial para o nosso caso de estudo, que é o arquipélago da Madeira. Como explicar esta atração e este transpor de fronteiras proibidas, mormente da parte dos católicos que aderiram à Maçonaria, continuando a sua prática católica? Ao longo deste estudo vamos tentar compreender a Maçonaria como um movimento e uma instituição, latu sensu assim definida, que procurou constituir elites com um certo nível de preparação intelectual e de influência social.

\begin{abstract}
Centuries of controversy, prohibitions and mutual attacks have made Freemasonry and the Catholic Church somewhat irreconcilable adversaries. Nonetheless, the attraction Freemasonry has had for members of the Church in its origins is still paradoxical and continues nowadays. In the ranks of Freemasonry, and particularly in the Masonic leaderships, there were members from the Catholic Church, especially from its secular and regular clergy. If this was true at an international level, it was even more so in catholic countries where masonic obedience was eloquently implemented, especially in our case study, which is the archipelago of Madeira. How can we explain this attraction and this crossing of forbidden frontiers, especially of Catholics who joined Freemasonry, while continuing their catholic practice? Throughout this study we will try to understand Freemasonry as a movement and an institution, in latu sensu, that sought to constitute elites of high intellect and social influence.
\end{abstract}




\section{Maçonaria como heresia: Histórico de dissidências e conflitos com a Igreja católica}

As primeiras notícias relativas à atividade da Maçonaria em Portugal datam da virada dos anos 20 para os anos 30 do século XVIII. Segundo os principais historiadores da Maçonaria portuguesa, neste período encontravam-se em funcionamento duas lojas maçónicas, na cidade de Lisboa, a dos Hereges Mercantes e a Casa Real dos PedreirosLivres da Lusitânia. A primeira sabe-se que foi fundada por volta do ano de 1727, tendo solicitado regularização à Grande Loja de Londres, em 1735. Era composta, sobretudo, por negociantes ingleses protestantes. Já a Casa Real dos Pedreiros-Livres da Lusitânia teria iniciado suas atividades por volta de 1733 e encerrado por volta de 1738 .

O processo de inserção da sociabilidade ${ }^{1}$ maçónica em Portugal foi complexo e coincidiu com a primeira condenação formal da Maçonaria pela Igreja católica ${ }^{2}$. No dia 14 de setembro de 1737, o Cardeal André Hercule de Fleury, primeiro-ministro de Luís $\mathrm{XV}$, proibiu todas as reuniões secretas e a formação de associações desse tipo sob qualquer pretexto. As condenações à Maçonaria não vinham apenas dos papas, mas de outros elementos do clero. Em 1735, idêntica proibição emanara na Holanda, cujo exemplo parece ter sido seguido por muitos governos da Europa ${ }^{3}$. A 28 de abril de 1738, o Papa Clemente XII, através da bula In Eminenti Apostolatus Specula, acompanhou o cardeal francês, proibindo os católicos de se filiarem na lojas maçónicas que tinham começado a surgir na Europa, sob pena de excomunhão. Ordenava aos clérigos que largassem essas práticas, assinalando assim a total incompatibilidade entre o juramento e o segredo das obediências maçónicas e a condição de cristão integrado na Igreja Católica Romana.

Após esta condenação, muitas outras se seguiram. Bento XIV, sucessor de Clemente XII, 13 anos depois da primeira condenação papal da Maçonaria, veio reafirmar a condenação do seu antecessor, publicando a bula Provida Romanorum, em 1751. Bento XIV assegurou que a absolvição da excomunhão decretada a vários fiéis que pertenciam à Maçonaria só tinha lugar pelo arrependimento e a violação das leis católicas, em especial por pertencerem à Maçonaria. Deste modo, corroborou a posição de Clemente XII.

O Papa Pio VII, em 1821, seguiu o mesmo caminho, publicando a bula Ecclesiam A Jesu Christo, cuja intenção foi a de confirmar as bulas de Clemente XII e

\footnotetext{
${ }^{1}$ Baseamo-nos na articulação que o autor Alexandre Mansur Barata faz do termo à questão da Maçonaria. O termo sociabilidade foi articulado como conceito histórico por Maurice Agulhon, em sua obra Pénitents et Francs-Maçons de l'Ancienne Provence (1984, 1. ${ }^{\mathrm{a}}$ edição 1966). O conceito passa a ser referenciado, a partir desse estudo, como um novo campo de direcionado para a dinâmica da vida associativa em um lugar e tempo definidos. Alexandre Mansur Barata, Maçonaria, sociabilidade ilustrada e Independência do Brasil (1790-1822) (São Paulo-Juiz de Fora: Annablume-Ed. UFJF, 2006), 22.

${ }^{2}$ Barata, Maçonaria, sociabilidade ilustrada e Independência do Brasil, 127.

${ }^{3}$ José Antonio Ferrer Benimeli, G. Caprile, Maçonaria e Igreja Católica, trad. De V. Alberton (São Paulo, edições Paulinas, 1983), 24.
} 
Bento XIV. Pio VII condenou também a Carbonária, associada à Maçonaria e a todas as sociedades secretas, que, segundo ele, tinham como objetivo a conspiração e o crime.

Ao longo do tempo, continuaram as condenações papais das associações secretas, e como tal da Maçonaria, mas isso não significou um recuo destas, mesmo entre o clero. Segundo o historiador José Antonio Ferrer Benimeli, a Igreja católica condenou uma associação sobre a qual muito pouco conhecia e de cujos objetivos desconfiava ${ }^{4}$. Na medida em que a Maçonaria começou a expandir-se pelo continente europeu, vários governos seculares, tanto católicos quanto protestantes, receosos do carácter secreto da associação, adotaram medidas para coibir a sua atuação: Holanda (1735); Genebra (1736), França (1737), Suécia e a cidade de Hamburgo (1738). Esses governos mostravam temor ao segredo que envolvia as práticas maçónicas, bem como o juramento prestado na iniciação de um novo membro, que supostamente ameaçava os traidores da Maçonaria com penas que somente as autoridades constituídas poderiam executar. É necessário perceber a Maçonaria como um corpo de ideias e de ritualidades que se apresentaram, aos olhos da Igreja, como subversivas no âmbito dos modelos sociais e políticos vigentes. Conforme afirmam os historiadores Fernanda Santos e José Eduardo Franco, a Igreja, através da sua alta hierarquia e como instituição religiosa tutelar das sociedades do Antigo Regime, entendeu a Maçonaria como "uma instituição concorrencial que pedia uma fidelidade que alegadamente não poderia ser partilhada com a fidelidade religiosa à Igreja com o mesmo grau de vinculação" ${ }^{\text {. }}$

A condenação da Maçonaria pelo papa Clemente XII somou, ao conjunto de justificativas utilizadas como razões de Estado para repressão dos maçons, um fundamento de natureza religiosa. Não eram apenas os governos seculares que eram ameaçados pelas reuniões secretas dos maçons, mas também a fé católica, o que, no caso português, significou a inclusão do pertencimento à Maçonaria no rol dos crimes circunscritos à jurisdição inquisitorial.

Essa primeira condenação da Maçonaria pela Igreja católica tornou-se conhecida em Portugal em julho de 1738 e foi divulgada oficialmente a 28 de setembro do mesmo ano, através de um edital assinado pelo Inquisidor Geral, cardeal D. Nuno da Cunha, que, além de reproduzir os termos gerais da bula papal, exortava a todos que denunciassem, nu prazo de trinta dias e sob pena de excomunhão, pessoas conhecidas que frequentassem as lojas maçónicas ${ }^{6}$.

Segundo o historiador Francisco Bethencourt, a Inquisição funcionou com poderes delegados pelo papa para a perseguição das heresias. No momento da sua instalação em Portugal, em 1536, pela bula papal Cum ad nihil magis, a Inquisição concentrou as suas forças na punição da prática do segredo, pelos cristão novos, de

\footnotetext{
${ }^{4}$ Ferrer Benimeli coord., La Masoneria en la España del siglo XIX: II Symposium de Metodología Aplicada a la Historia de la Masonería Española (Léon: Junta de Castilla y Leon, 1987), 70-72.

${ }^{5}$ Fernanda Santos e José Eduardo Franco, "A insustentável leveza das fronteira: Clero Católico na Maçonaria e a questão do Anticlericalismo e do Antimaçonismo em Portugal", REHMLAC 2, no. 2 (diciembre 2010-abril 2011): 56, https://revistas.ucr.ac.cr/index.php/rehmlac/article/view/6596/6287

${ }^{6}$ Edital de Fé, 28/09/1738, reproduzido em A. H. de Oliveira Marques, História da Maçonaria em Portugal (Lisboa: editora Presença, 1990), vol. 1, 29-30.
} 
valores e costumes judaicos. No decorrer dos seus quase três séculos de existência, esse tribunal eclesiástico possuiu uma enorme plasticidade, sofrendo alterações sensíveis no que se refere às suas funções. Exemplos dessa plasticidade podem ser percebidos tanto na relação com o poder real, quanto no conjunto de crimes sob sua jurisdição. Assim, se em alguns momentos a Inquisição se encontrou subordinada ao poder real, em outros ela possuiu quase que uma autonomia absoluta. Criada para perseguir os cripto-judeus, já no século XVII vários outros costumes foram considerados crimes, perseguidos e punidos, tais como a bigamia, a sodomia, a blasfêmia, a solicitação, as práticas mágicas e supersticiosas ${ }^{7}$.

No caso português, a Inquisição foi ao mesmo tempo um tribunal eclesiástico e um tribunal da Coroa. É fundamental ter em conta essa dualidade para entender a inclusão do crime de pertencimento à Maçonaria na jurisdição inquisitorial. Ao serem considerados como suspeitos de heresia, os maçons eram considerados como maus católicos e maus vassalos, concomitantemente.

Após a publicação da bula In Eminenti, a ação inquisitorial perseguiu os maçons entre os anos de 1742 a 1744. Nesse período, tinha sido fundada uma nova loja maçónica em Lisboa, constituída por franceses e presidida por John Coustos ${ }^{8}$, um suiçoque pretendia se estabelecer no Brasil caso não tivesse sido processado pela Inquisição de Lisboa'.

Em 1751, uma nova bula papal confirmou a condenação da Maçonaria feita por Clemente XII. Tratou-se da bula Providas de Bento XIV, publicada a 18 de maio daquele ano. Segundo aquilo que é apontado por Ferrer Benimeli, além das motivações já expressas na bula anterior, ampliaram-se as razões para que a maçonaria fosse novamente proibida. Entre esses motivos, estavam o fato de a instituição reunir homens de todas as religiões; o carácter secreto da Maçonaria, que era entendido como um mecanismo para encobrir práticas criminosas; o juramento que era prestado, comprometendo-se os membros em nada revelar sobre os assuntos tratados no interior da sociedade maçónica; o fato de as reuniões contrariarem as leis civis e eclesiásticas, uma vez que aconteciam sem a permissão das autoridades constituídas; o fato de que muitos governos seculares já haviam adotado medidas para proibi-las e ainda a demonização constante que recaía sobre tais sociedades ${ }^{10}$.

Oliveira Marques observou que, depois das perseguições da década de 1740, a Maçonaria em Portugal só voltaria a ter uma atividade relativa durante a segunda

\footnotetext{
${ }^{7}$ Francisco Bethencourt, História das Inquisições: Portugal, Espanha e Itália (séculos XV-XIX) (São Paulo: Companhia das Letras, 2000), 31.

${ }^{8}$ A trajetória de John Coustos pode ser conhecida através da sua, publicadas em Londres, depois do tempo em que ficou preso em Lisboa (1746). John Coustos, The Sufferings of John Coustos for Freemasonry and for His Refusing to Turn Roman Catholicin the Inquisition (London: Printedby W. Strahan, for the author, 1746). Giovanni Tarantino, "The Mysteries of Popery Unveiled: Affective Language in John Coustos' and Anthony Gavín's Accounts of the Inquisition”, in Spaces for Feeling: Emotions and Sociabilities in Britain, 1650-1850, ed. Susan Broomhall (Londres: Routledge, 2015), 3551 .

${ }^{9}$ Barata, Maçonaria, sociabilidade ilustrada e Independência do Brasil, 131.

${ }^{10}$ Ferrer Benimeli, La Masoneria en la España del siglo XIX, 94-95.
} 
metade do governo pombalino ${ }^{11}$. O estabelecimento do Conde de Lippe em Portugal, a convite de Pombal, para reorganizar os exércitos, bem como a presença de grandes comunidades de comerciantes ingleses e franceses foram consideradas razões para esse ressurgimento, que não contou com uma oposição ostensiva por parte do governo pombalino ${ }^{12}$.

A chegada ao poder, em 1755, de uma nova corrente, encabeçada por Sebastião José de Carvalho e Melo, futuro conde de Oeiras e marquês de Pombal, político que convivera por toda a Europa com a ala progressista do espírito das Luzes propagandeado pela Maçonaria e que possivelmente fora nela iniciado, deu novo impulso ao desenvolvimento da instituição maçónica em Portugal. A Portugal chegavam também muitos outros maçons, nacionais e estrangeiros (vindos tanto da Europa como da América), que, aos poucos, começaram a criar lojas por todo o território do país, expandindo a Maçonaria para as ilhas adjacentes da Madeira e dos Açores. Embora não estivesse ainda estruturada como Obediência, a Maçonaria portuguesa começava a ser conhecida interna e externamente, contando no seu seio tanto lojas de civis como lojas compostas estritamente por militares, que funcionavam ligadas aos diferentes regimentos. Em 1773, o conde de Atalaia representou o Oriente de Portugal no banquete da tomada de posse do novo grão-mestre do Grande Oriente de França. A Maçonaria começou a expandir sua influência, constituindo-se, para muitos, como grupo de pressão e de interferência política. Na ilha da Madeira, a influência maçónica levou a perseguições, sendo os principais dirigentes presos e enviados para Lisboa, onde foram interrogados e, um pouco mais tarde, colocados em liberdade. A tolerância do governo de Marquês de Pombal ficou patente no novo regimento dado à Inquisição portuguesa, em 1774, onde se omitia da lista dos crimes o fato de se ser maçon. Ficavam, assim, postas de parte as condenações impostas pelas bulas papais. Especialmente nos primeiros dois séculos da história da Maçonaria, séculos XVIII e XIX, a elite mais bem preparada intelectualmente estava entre o clero católico.

Se os movimentos antimaçónicos se originaram, na sua grande maioria, na força da Igreja católica ${ }^{13}$, importa notar que, desde o século de entrincheiramento dogmatizante que foi o século XIX, neocatólico e conservador, no qual a maçonaria entrou frontalmente em guerra propagandística contra a Igreja, que houve uma evolução importante para esfriar o acirrar do velho conflito ${ }^{14}$.

\section{O contexto insular no surgimento da maçonaria português}

Durante a segunda metade do século XVIII, a Maçonaria tinha erguido Lojas em cinco centros urbanos, tais como Lisboa, Porto, Coimbra, Valença do Minhoe Funchal.

\footnotetext{
${ }^{11}$ Marques, História da Maçonaria em Portugal.

${ }^{12}$ Barata, Maçonaria, sociabilidade ilustrada e Independência do Brasil, 133.

${ }^{13}$ Rui Ramos, “Antiçamonismo", em Dança dos Demónios - Intolerância em Portugal, orgs. António Marujo e Franco (Lisboa: Círculo de Leitores, 2009), 374.

${ }^{14}$ Santos e Franco, "A insustentável leveza das fronteira", 64.
} 
Estas eram Lojas de importância relativa. O historiador Joaquim Veríssimo Serrão referiu um papel interventivo da Maçonaria em Portugal a partir de 1762, quando os oficiais do conde de Lippe conquistaram adeptos em diversas franjas do tecido social, na nobreza, no exército, na diplomacia, na mercancia e na cultura ${ }^{15}$. No ano de 1770 , o governador e capitão geral da ilha da Madeira, João António de Sá Pereira determinou a prisão, bem como a apreensão dos papéis e de alguns objetos maçónicos pertencentes a Aires de Ornellas Frazão, Francisco d'Alincourt e BartholomeuAndrieu ${ }^{16}$.

Em Portugal, os bispos seguiram as recomendações de Roma e os reis participaram, também, nesse processo. Assim, a 12 de Agosto de 1817, D. João VI, então no Brasil, condenou as sociedades secretas ao ponto de considerá-las tão impolíticas quanto perigosas. Aos monarcas interessava extinguir nos seus estados semelhantes associações ${ }^{17}$.

A primeira loja maçónica portuguesa que se estabeleceu, na ilha da Madeira, foi fruto do intenso tráfico comercial que se fazia entre a Ilha, a Inglaterra e as suas colónias na América e outras cidades europeias. Em 1770, numa longa carta ao Marquês de Pombal, o Capitão-general da Madeira, João António de Sá Pereira, denunciou a existência de pedreiros-livres na Madeira, referindo o fato de estes elementos serem originários das classes sociais mais altas, ou seja, das elites.

Os madeirenses que estudavam e negociavam no estrangeiro foram largamente influenciados pelo espírito revolucionário que crescia na Europa e na América. Era também referido, na altura, que o maior perigo vinha de alguns militares franceses que aproveitaram o clima social propício para fundarem lojas maçónicas, em união com cidadãos portugueses.

Ainda em 1770, começaram a aparecer denúncias a esse respeito, na Inquisição de Lisboa. Sá Pereira, já nesta altura, aplicou penas de desterro para as zonas rurais da Madeira, como aconteceu com o médico Manuel Caetano, com o nobre e proprietário Ayres de Ornelas Frazão e com o médico Julião Fernandes da Silva. Estas perseguições prosseguiram nos anos seguintes, o que mostrava que a Maçonaria na Madeira já existia de forma organizada, a ponto de nesse ano ter havido uma violenta perseguição aos maçons madeirenses, mesmo antes da sua organização no continente.

A Maçonaria tomou nova expansão depois da chegada de Barthélem y Andrieudu Bouly, à lha da Madeira. Maria Thirps, mulher de Ayres de Ornelas, declarava que os engenheiros militares franceses Francisco d'Allincourt e Andrieudu Bouly, que tinham sido presos entre os dias 6 e 27 de Novembro de 1770, eram pedreiros-livres $^{18}$. Este último, no seu depoimento, diz que a Loja do Funchal já estava

\footnotetext{
${ }^{15}$ Joaquim Veríssimo Serrão, História de Portugal - O Despotismo Iluminado (1750-1807) (Lisboa: Editorial Verbo, 1981), vol. VI, 434.

${ }^{16}$ Barata, Maçonaria, sociabilidade ilustrada e Independência do Brasil, 133.

${ }^{17}$ António Egídio Fernandes Loja, A luta do poder contra a Maçonaria: quatro perseguições no século XVIII (Lisboa: Imprensa Nacional Casa da Moeda, 1986), 247.

${ }^{18}$ Fernandes Loja, A luta do poder contra a Maçonaria, 257.
} 
constituída mesmo antes dos militares franceses terem chegado à Madeira, da qual eram sócios Ayres de Ornelas Frazão, Joaquim António Pedroso e D. José de Brito ${ }^{19}$.

Ainda nesse ano, houve a primeira perseguição contra os membros da Loja maçónica do Funchal, associando-se a ela o Governador e o Bispo da Diocese, embora este tenha desempenhado um papel bastante passivo, até porque neste período, com o Marquês de Pombal no governo, os interesses do Estado sobrepunham-se aos da Igreja. Tudo indicava que a perseguição aos maçons na ilha da madeira não fizesse parte de uma estratégia organizada pela Estado português, mas fosse fruto de desavenças pessoais entre o próprio governador e Aires de Ornellas Frazão. O governador ter-se-ia aproveitado do fato de este ser maçom para incriminá-lo e enviá-lo, juntamente com Francisco d'Alicourt, para Lisboa, no início de $1771^{20}$. Nos anos 90 do século XVIII, a Maçonaria retomou atividade, na ilha da Madeira, integrando como membros alguns nobres educados em Inglaterra, tais como Brito Herédia, Miguel Carvalho e o Padre Alexandre José Correia ${ }^{21}$.

Cumpre-nos notar que a Madeira foi, de algum modo, um território de ensaio e de lançamento da Maçonaria Portuguesa e de lojas constituída por iniciativa de portugueses. Neste sentido, escreve o historiador António Loja que "os mações lisboetas parecem ter a clara noção de que a ideologia maçónica chegara até eles através das lojas madeirenses" ${ }^{22}$. Um destacado membro da maçonaria lisboeta que viria a ser nos anos 90 do século XVIII perseguido por Pina Manique e julgado em Lisboa pela Inquisição, o cónego D. André de Morais Sarmento, foi iniciado na Ilha da Madeira e deve-se a ele aquele que é considerado o primeiro escrito português de explicação daquela que podemos chamar a "carta de identidade maçónica"para os aprendizes, a "Explicação da Maçonaria aos recém recebidos",23.

\section{As acusações à Maçonaria na ilha da Madeira}

Luz Soriano, na sua obra História da Guerra Civil ${ }^{24}$, refere que Jean Joseph d'Orquigny foi quem espalhou a fama dos pedreiros livres, munido de uma carta patente de grão comendador, assinada pelo duque de Orleans, grão-mestre da grande Loja de Paris ${ }^{25}$.

\footnotetext{
${ }^{19}$ Fernandes Loja, A luta do poder contra a Maçonaria, 266-267.

${ }^{20}$ Fernandes Loja, A luta do poder contra a Maçonaria, 133.

${ }^{21}$ Maria da Graça Silva Dias, "Anglismo na Maçonaria em Portugal no limiar do século XIX”, Análise Social XVI , nos. 61-62 (1980): 401.

${ }^{22}$ António Loja, A luta do poder contra a Maçonaria: quatro perseguições no século XVIII (Lisboa: Âncora, 2017), 301. A primeira edição deste estudo académico de referência foi realizada nos anos 80 pela Imprensa Nacional Casa da Moeda.

${ }^{23}$ ANTT: Inquisição de Lisboa, Proc., no. 8614, 6v, 7 e 7v.

${ }^{24}$ Simão José da Luz Soriano, História da Guerra Civile do estabelecimento do governo parlamentar em Portugal (Lisboa: Imprensa Nacional, 1871), tomo I, 396.

25 Álvaro Rodrigues de Azevedo, Dicionário Universal Português Ilustrado (artigo "Maçonaria", 1884), 388-399.
} 
A Maçonaria madeirense cresceu e organizou-se em força com a presença dos militares ingleses na Ilha. A sua composição consistia em um grande número de pessoas influentes locais, entre elas muitos nobres, clérigos e burgueses. Havia um bom relacionamento entre os cônsules ingleses e os maçons madeirenses, de modo muito particular Henry Veitch. Os ingleses ocuparam a Madeira por duas vezes, chegando a ilha a ser um protetorado inglês entre julho de 1801 e abril de 1802 e de dezembro de 1807 a outubro de 1814. A Maçonaria conheceu então um período de crescimento, visível nos acontecimentos políticos de 1820 a 1823, manifestando-se organizada e atuante. Alguns dos maçons foram acusados, julgados e condenados, uns a degredo e outros a prisão ${ }^{26}$. A Maçonaria madeirense estava subordinada ao Grande Oriente de Lisboa, com autonomia provincial. A Maçonaria funchalense estabeleceu a primeira tipografia e o primeiro jornal periódico na Madeira, O Patriota Funchalense ${ }^{27}$, publicado pela primeira vez a 2 de Julho de 1821, terminando a 16 de Agosto de 1823, com o desterro do seu proprietário, Nicolau Bettencourt Pita.

O período histórico e político entre 1820 e 1823 foi extremamente conturbado, desde que se realizaram as primeiras eleições para reunir as Cortes Constituintes até à Vilafrancada de 1823. Entre os vários acontecimentos conturbados encontram-se o golpe militar da Martinhada (1820), a extinção do Santo Ofício (1821), a Constituição elaborada pelas Cortes Constituintes (1822) e a proclamação da independência do Brasil (7 de setembro de 1822) ${ }^{28}$.

Segundo Emanuel Janes, a alçada e a devassa ${ }^{29}$ de 1823 , ordenadas na sequência da Vilafrancada que levou à dissolução das Cortes, à suspensão da Constituição política de 1822 e à restauração do Governo Absoluto por D. João VI, tinham ordens para perseguir, processar, julgar e prender todos aqueles que estivessem relacionados com a Maçonaria, então acusada de conspirações perversas e atividades subversivas. O motivo para o seu desencadeamento foi a intensa atividade política que os liberais tinham na Ilha, a atuação na revolução de 1820 e o papel desempenhado na elaboração da Constituição de 1822 , bem como as várias tentativas levadas a cabo para restabelecer a Constituição e o Governo Liberal.

A alçada causou situações de extrema tensão entre os madeirenses que, chamados a testemunhar contra os liberais, tiveram de contrariar os interesses dos representantes da justiça, destacando-se a violenta perseguição exercida sobre os

\footnotetext{
${ }^{26}$ Emanuel Janes, "Igreja e Maçonaria na Madeira: a Alçada de 1823", em Diocese do Funchal - A Primeira Diocese Global: História, Cultura e Espiritualidades, dirs. Franco, João Paulo Oliveira e Costa (Funchal/Lisboa: Esfera do Caos/Diocese do Funchal, 2015), vol. I, 531.

${ }^{27} O$ Patriota Funchalense, vol. 1, no. 1, 2 de julho de 1821 a vol. 3, no. 167, 8 de fevereiro de 1823 , Funchal, Typographia do Patriota, 1821-1823, in Jornais e Revistas Portugueses do século XX 2, coord. e org. Gina Guedes Rafael e Manuela Santos (Lisboa: BNP, 1998-2002), 162.

28 Susana Marta Delgado Pinheiro, "Religião, sociedade e vintismo no Jornal Astro da Lusitânia", Lusitania Sacra 16 (2004): 345-358.

${ }^{29}$ O termo jurídico "alçada" refere-se ao tribunal que se deslocava pelos povoados com o propósito de administrar justiça. O termo jurídico "devassa" refere-se a uma investigação para apurar um crime, ou seja, a pesquisa de provas, observação e inquirição de testemunhas para averiguação de um ato criminoso. As expressões "fechar a devassa" e "tirar a devassa" são usados, respectivamente, para se referir ao prosseguimento ou não prosseguimento de uma ordem judicial e a instauração de um processo criminal.
} 
clérigos que mostrassem alguma relação com esta associação secreta. As perseguições que se seguiram vieram perturbar o normal crescimento das ideias maçónicas na Madeira, fazendo com que a Maçonaria tivesse uma vida curta no arquipélago. Os católicos que estiveram envolvidos com esta associação secretaforam considerados hereges, mesmo quando os depoimentos das testemunhas eram escassos ou até contraditórios $^{30}$.

A carta do padre António José Nunes Júnior ao Conde de Subserraacusou, diretamente, o bispo do Funchal, D. Francisco José Rodrigues de Andrade (1821-1834) de ser o grande responsável pela alçada e pedia a sua exoneração, substituição e imediata saída da ilha da Madeira,

a fim de sossegar os pacíficos cidadãos desta Província, não só por que é um chapado ignorante, Infantista, esturrado, intrigante, inimigo de homens de bem, seja qual for o seu estado, bêbado todas as tardes, não vai à Sé pregar, não só por não saber arranjar uma homilia, como porque é tão mandrião, que nem quer decorar algum discurso que lhe fazem para ele repetir, enfim para perseguição dos clérigos, nomeou para Vigário Geral um cónego leigaço e estuporado, que nem português sabe escrever, quando aliás tinha no Cabido um cónego formado e na cidade dois clérigos também formados e que advogam, tudo isto com o sinistro e malvado fim de governar o Bispado despótica e tiranamente, atacando os vigários de maior probidade, suspendendo-os escandalosamente e pondo em seu lugar clérigos de uma péssima conduta e tão péssimos que estão vivendo pública e descaradamente amancebados, tendo filhos e até acusados como tais em Juízo. [...]. Este Santo Prelado, no ano passado, quando esteve aqui a Alçada, meteu-se com o Presidente dela, o Robespierre Mello Freire e sabendo do Presidente que as testemunhas perguntadas nada diziam, porque realmente nada tinha havido do que se apontava na Carta Régia que servia de corpo de delito e como o Bispo tinha sido o móvel principal ou o íman que tinha atraído a este povo aquele flagelo, convencionou com o dito Presidente para lhe mandar certas testemunhas aliciadas pelos cónegos $[\ldots]^{31}$.

No entanto, apesar desta denúncia, o bispo manteve-se nesta diocese até ao seu falecimento, em 1834, ano em que terminou a Guerra Civil entre liberais e absolutistas, tendo sido implantado, definitivamente, o liberalismo em Portugal. A Maçonaria na Madeira foi dispersada e posteriormente dizimada, sendo que a instituição só voltou a ser referida na década de 70 do século XX. Emanuel Janes apontou como causas deste desaparecimento os acontecimentos políticos de 1828, a Alçada, nesse ano, na Madeira, chefiada pelo desembargador Maciel Monteiro, a pronúncia de 216 pessoas e a prisão de 101 liberais e maçons, bem como os degredos que se seguiram; a emigração, o desterro do cadafalso, onde caíram muitos portugueses, e o despotismo miguelista ${ }^{32}$.

\footnotetext{
${ }^{30}$ Janes, "Igreja e Maçonaria na Madeira", 532.

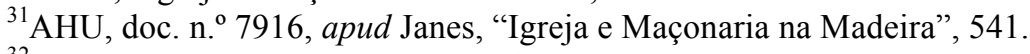

32 Janes, "Igreja e Maçonaria na Madeira”, 541.
} 


\section{Conclusão}

A criação da loja do Funchal inaugurou a maçonaria lusitana. Os portugueses participantes dessa loja foram, sobretudo, da nobreza da terra, alguns deles iniciados em Londres. Em 1792, as lojas eram mistas, compondo-se de membros ingleses e portugueses, -nobres e eclesiásticos. Em Portugal, o desenvolvimento da atividade maçónica se deveu ao contato com estrangeiros, ingleses e sobretudo franceses, homens de negócios e militares ${ }^{33}$.

A maçonaria formou-se ainda, em seus primórdios, em universo protestante. Os rituais iniciáticos, de estruturação esotérica, implicavam compromissos, juramentos, fidelidades e obediências paralelas e/ou em concorrência com processos semelhantes de vinculação aos da Igreja. Esse fato suscitou sempre grandes suspeitas, dúvidas e receios da parte dos guardiães da ortodoxia católica ${ }^{34}$.

\section{Bibliografia}

Agulhon, Maurice. Pénitents et francs-maçons de l'ancienne Provence: essais sur la sociabilité méridionale. Paris: Fayard, 1984.

Azevedo, Álvaro Rodrigues de. Dicionário Universal Português Ilustrado, 1884.

Barata, Alexandre Mansur. Maçonaria, sociabilidade ilustrada e Independência do Brasil (1790-1822). São Paulo-Juiz de Fora: Annablume-Ed. UFJF, 2006.

Bethencourt, Francisco. História das Inquisições: Portugal, Espanha e Itália (séculos $X V$-XIX). São Paulo: Companhia das Letras, 2000.

Coustos, John. The Sufferings of John Coustos for Freemasonry and for His Refusing to Turn Roman Catholic in the Inquisition. London: Printed by W. Strahan, for the author, 1746.

Ferrer Benimeli, José Antonio. G. Caprile, Maçonaria e Igreja Católica. Traduzido por V. Alberton. São Paulo: edições Paulinas, 1983.

Ferrer Benimeli, José Antonio coord. La Masoneria en la España del siglo XIX: II Symposium de Metodología Aplicada a la Historia de la Masonería Española. Léon: Junta de Castilla y Leon, 1987.

Janes, Emanuel. "Igreja e Maçonaria na Madeira: a Alçada de 1823". Em Diocese do Funchal - A Primeira Diocese Global: História, Cultura e Espiritualidades. Dirigido por José Eduardo Franco e João Paulo Oliveira e Costa. Funchal/Lisboa: Esfera do Caos/Diocese do Funchal, 2015.

Loja, António. A luta do poder contra a Maçonaria: quatro perseguições no século XVIII. Lisboa: Âncora, 2017.

Marques, A. H. de Oliveira. História da Maçonaria em Portugal. Lisboa: editora Presença, 1990.

\footnotetext{
${ }^{33}$ Rui Ramos, “Antiçamonismo”, 329.

${ }^{34}$ Santos e Franco, “A insustentável leveza das fronteira”, 69.
} 
Pinheiro, Susana Marta Delgado. "Religião, sociedade e vintismo no Jornal Astro da Lusitânia”. Lusitania Sacra 16 (2004): 345-358.

Rafael, Gina Guedes e Manuela Santos coord. e org. Jornais e Revistas Portugueses do século XX. Lisboa: BNP, 1998-2002.

Ramos, Rui. “Antiçamonismo”. Em Dança dos Demónios - Intolerância em Portugal. Organizado por António Marujo e José Eduardo Franco. Lisboa: Círculo de Leitores, 2009.

Santos, Fernanda y José Eduardo Franco. "A insustentável leveza das fronteiras: Clero Católico na Maçonaria e a questão do Anticlericalismo e do Antimaçonismo em Portugal". REHMLAC 2, no. 2 (diciembre 2010-abril 2011), 53-65, https://revistas.ucr.ac.cr/index.php/rehmlac/article/view/6596/6287

Serrão, Joaquim Veríssimo. História de Portugal - O Despotismo Iluminado (17501807). Lisboa: Editorial Verbo, 1981.

Soriano, Simão José da Luz. História da Guerra Civile do estabelecimento do governo parlamentar em Portugal. Lisboa: Imprensa Nacional, 1871.

Tarantino, Giovanni. "The Mysteries of Popery Unveiled: Affective Language in John Coustos' and Anthony Gavín's Accounts of the Inquisition”. Em Spaces for Feeling: Emotions and Sociabilities in Britain, 1650-1850. Editado por Susan, Broomhall. London: Routledge, 2015.

\section{Anexo}

Explicação da Maçonaria aos Recém-recebidos.

Arquivo da Torre do Tombo, Tribunal do Santo Ofício, Inquisição de Lisboa, Mç. 28, Processo 8614.

PT-TT-TSO-IL-28-8614_m0017 a 0019. () /img. 17 - p. 9/

Explicação da Maçonaria aos Recém Recebidos.

Quem tal diria, Mações, que Vós Venhais achar uma Sociedade de honrae de Virtude! Esta Sociedade tão Antiga como os Homens tem sido olhada pelos mesmos homens com olhos fascinantes aplicando-lhe ideias umas exóticas, outras criminosas todas aéreas, e poucas Verdadeiras.

Eu não pretendo fazer-vos um Discurso pomposo na vossa augusta recepção: entre nós reina sempre a simplicidade e moderação: unicamente vou expor-vos as vossas obrigações que acabais de Contrair. E a primeira é aquela imposta a todo o homem, de conservar um coração incorrupto, apartado dos vícios, despido das funestas paixões e honrado das virtudes que inspira a razão e a Humanidade. Isto significa a vossa entrada despidos de todos os metais, que significam os vícios: meios nus, meios vestidos. Nus dos vícios, vestidos só das Virtudes. A segunda uma particular obediência e fidelidade ao Rei e à Pátria segundo o legítimo poder e governo a que fôreis sujeitos. 
Esta é a honrada e impreterível obrigação do Mação, pois que ele é pela sua profissão um homem de caridade, de união e de Virtude Social, que sem obediência ao poder soberano do Príncipe não seria mais que um rebelde, insocial e um cismático da união e da verdadeira Maçonaria, que só quer união, caridade, paz e obediência legítima. A terceira obrigação é de socorrer os vossos irmãos nas suas necessidades irmãos que vos forem conhecidos por um exame maduro e exato.

E é por isto que contraístes a quarta obrigação de não revelar o vosso segredo, que consiste nos sinais, palavras e toques que se vos têm ensinado; porquanto, revelados eles, nos veríamos inundados de infinitos irmãos apócrifos e necessitados, e viria uma sociedade, tão virtuosa e útil, a desvanecer-se e aprofanar-se.

Vedes aqui em suma o que é ser Mação. Vedes aqui o que viestes achar. Vedes /img. 18 - p. 10/ aqui os nossos segredos. E se vós tenhais outras ideias desta augusta sociedade, conhecei agora que é que é o mundo e o que é o povo, sempre ansioso de saber o que ignora, aplica tudo o que há de mais extravagante ao objeto que não conhece.

Entre nós o que há mais agradável, além de contar com tantos Irmãos, quantos mações, é a igualdade que se observa e que se simboliza no nível. Luiz 14, Frederico e Garganelli tinham entre nós o mesmo lugar que qualquer outro. À mesa tinham a mesma obediência, cantavam, se os mandavam, e bebiam à saúde que se lhe propunha com a mesma alegria, sem soberania, nem distinção. Todos somos iguais. E como entre nós é acautelado e mesmo proibido tratar de matérias que não sejam puramente maçónicas, e menos de Religião, ou de Estado; esta a razão porque reconhecemos por irmãos quaisquer mações do mundo, contanto que não sejam ateus; porque estes, se é que os pode haver, não poderão entrar em sociedade de virtudes como esta, pois não podem ser fieis, nem ter caridade, nem sistema algum social e da Humanidade. Eles não podem jurar por um Deus em que não creem; não podem por isso mesmo ter obediência ao Príncipe que tem o poder de Deus; e não podem finalmente figurar na sociedade senão a imagem de um contraditório. Outro qualquer homem, porém, pode entrar na nossa sociedade. Contanto que ele pratique as obrigações dela, que como acabais de ouvir são comuns a todos os homens de qualquer Estado, ou Religião que sejam. E em breve vos tenho dito tudo o essencial da Maçonaria. Deresto tudo são acidentes, degraus e significações que embelezam,/img. 19 - p. 11/ mas que não mudam a substância. Por isso ouvireis falar do grau de Mestre, Companheiro, etc., que não são mais que adições de mais brilhante ornato e distinção e que alguns factos célebres da história lhe deram origem, mas que tudo recai em ser o Mação um homem honrado e verdadeiro irmão dos seus irmãos.

Dice.

Orador da Loge. 